Review

\title{
Poorly Differentiated Thyroid Carcinoma: Single Centre Experience and Review of the Literature
}

\author{
Maria Irene Bellini ${ }^{1,2, *}\left(\mathbb{D}\right.$, Marco Biffoni ${ }^{2,+}\left(\mathbb{D}\right.$, Renato Patrone ${ }^{3,+}{ }^{-}$, Maria Carola Borcea ${ }^{2}$, \\ Maria Ludovica Costanzo ${ }^{2}$, Tiziana Garritano ${ }^{2}$, Rossella Melcarne ${ }^{2}$, Rosa Menditto ${ }^{2}$, Alessio Metere ${ }^{4} \mathbb{D}$, \\ Chiara Scorziello ${ }^{2}$, Marco Summa ${ }^{2}$, Luca Ventrone ${ }^{2}$, Vito $D^{\prime}$ Andrea ${ }^{2} \mathbb{D}$ and Laura Giacomelli ${ }^{2}$

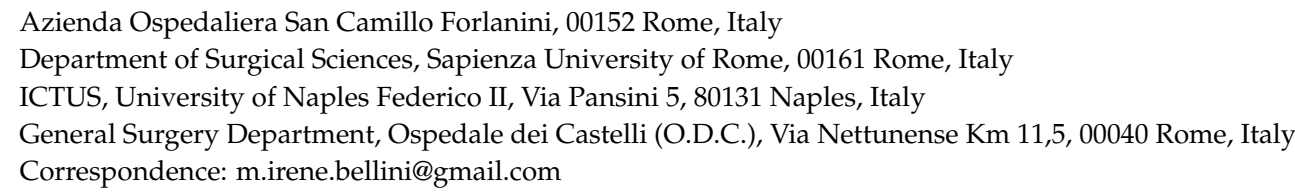

check for

updates

Citation: Bellini, M.I.; Biffoni, M.; Patrone, R.; Borcea, M.C.; Costanzo M.L.; Garritano, T.; Melcarne, R.; Menditto, R.; Metere, A.; Scorziello, C.; et al. Poorly Differentiated Thyroid Carcinoma: Single Centre Experience and Review of the Literature. J. Clin. Med. 2021, 10, 5258 https://doi.org/10.3390/ jcm 10225258

Academic Editor: Hermann Müller

Received: 22 October 2021

Accepted: 11 November 2021

Published: 12 November 2021

Publisher's Note: MDPI stays neutral with regard to jurisdictional claims in published maps and institutional affiliations.

Copyright: (C) 2021 by the authors. Licensee MDPI, Basel, Switzerland. This article is an open access article distributed under the terms and conditions of the Creative Commons Attribution (CC BY) license (https:// creativecommons.org/licenses/by/ $4.0 /$ )

\begin{abstract}
There is controversy in the literature regarding a distinct subset of thyroid carcinoma whose histologically classification falls between well-differentiated and anaplastic carcinomas, previously identified as 'poorly differentiated thyroid carcinoma' (PDTC), or 'insular carcinoma', in view of the peculiar morphological characteristics of the cell groupings. The correct diagnosis and treatment of this entity have important prognostic and therapeutic significance. In this review, we describe the epidemiology, diagnosis, and management of PDTC and report our single centre experience to add to the limited evidence existing in the literature.
\end{abstract}

Keywords: poorly differentiated thyroid cancer; total thyroidectomy; fine-needle aspiration cytology

\section{Epidemiology}

Poorly differentiated thyroid carcinoma (PDTC) is a rare disease, with an intermediate biological behaviour between well-differentiated (papillary and follicular) and undifferentiated (anaplastic) carcinoma; it can arise de novo in the gland or represent the evolution of an unknown differentiated carcinoma [1]. According to published studies, only $27 \%$ of cases are diagnosed correctly before surgical intervention; about $80 \%$ of PDTC have a poorly differentiated component of $\geq 50 \%$, and only $20 \%$ a lower percentage [2].

PDTC-reported incidence varies according to the geographic area considered: less than $1 \%$ of the whole thyroid cancers diagnosed in Japan [3], 2-3\% in North American [4], and $15 \%$ of those diagnosed in northern Italy [5]. The frequency is higher in older age and more prevalent in women (2.1:1 female to male ratio), particularly in areas of endemic goitre [6].

In PDTC, regional lymph nodal or distant metastases are common at diagnosis, with about $70 \%$ of patients presenting with locally advanced disease and a median 5 yearssurvival of $50-60 \%$ [7].

\section{Ultrasonographic Features}

Ultrasound (US) scan of the neck is an essential imaging technique for the evaluation of thyroid disease [8], and it is used to guide fine-needle aspiration cytologic (FNAC) and coreneedle biopsy procedures [9]. PDTC should be suspected when a circumscribed margin and an oval-to-round shape nodule of around $3-3.5 \mathrm{~cm}[7,10]$ are visualised, particularly if there is a concomitant irregular rich blood flow [11,12]. Notably, the so-called 'sword sign' is of particular importance, and it is observed only in poorly or undifferentiated thyroid carcinomas, with Colour Doppler US [13,14]. The reason for these appearances is supposed to be in relation to the abnormal circumscribed proliferation driven by genetic mutations 
and following atypical hyperplasia of thyroid follicular epithelial cells. This is commonly observed in immune diseases, as for example, in Hashimoto thyroiditis [15], and other goitre diseases where the abnormal lymphocytes stimulation might occur with higher frequency. Since only poorly differentiated or anaplastic carcinomas display external or internal jugular vein central invasion, Doppler US, preferrable during Valsalva manoeuvre, is vital to correctly plan the surgical strategy [16]. Microcalcifications presence could also be considered as a sign of malignancy in suspicious nodules, as they mostly represent psammoma bodies and might raise awareness of an occult ipsilateral or contralateral disease [17].

\section{Histological Examination}

Since its original description in 1983 by Japanese authors [18], the controversy surrounding the intrinsic nature of PDTC has been debated. Dr. Juan Rosai, who contributed significantly to this debate, observed that the main growth pattern was insular, therefore proposed the name of 'insular carcinoma' [19]. He also highlighted that this feature was already been described earlier on as a 'proliferating goitre' by Dr. Langhans, although such entity did not overlap with the solid, trabecular, and/or scirrhous patterns above identified by the Japanese authors. Thus, the controversy in the histological diagnosis, in addition to possible different geographical and ethnic factors are the main drivers of the ongoing debate.

From 2004, the WHO classified PDTC as a non-follicular non-papillary, thyroglobulinproducing thyroid carcinoma [20] with an intermediated behaviour between well-differentia ted and anaplastic carcinoma, whose distinctive hallmarks of adverse prognosis are high mitotic index and the presence of necrosis.

In 2006, a proposed diagnostic algorithm, known as the 'Turin proposal' defined the following diagnostic criteria [21]: (1) presence of a solid/trabecular/insular pattern of growth in a malignant (invasive) thyroid lesion of follicular derivation in the majority of the tumour; (2) lack of the conventional papillary carcinoma nuclear features; (3) presence of mitotic activity $>3 \times 10 \mathrm{HPF}$ or tumour necrosis or convoluted nuclei. Albeit simplifying the diagnosis, limitations inherent criteria reproducibility have been highlighted [22]—namely, what percentage of poorly differentiated tissue was needed in a tumour to allow for such a diagnosis and to affect patient prognosis, specifically considering the fact that the 2004 WHO classification did not offer a cut-off value.

Finally, the Memorial Sloan Kettering Cancer Centre (MSKCC) criteria for PDTC are less restrictive and only consider an elevated mitotic index ( $>5 / 10 \mathrm{HPFs})$ and/or tumour necrosis regardless of tumour growth patterns and nuclear aspects [23].

\section{Histological Variants of Poorly Differentiated Carcinoma}

The oncocytic variant of PDTC is even more controversial, and although it is recognised as an independent entity by the WHO [20], it was not originally included in the Turin proposal. The presence of necrosis in this tumour variant is the main characteristic, which is common to oncocytic lesions in general, where spontaneous or FNA-initiated infarction and focal necrosis often occur. It is important, however, to identify oncocytic PDTC early, as it is associated with worse outcomes in comparison with conventional PDTC [24].

\section{Cytology: The Bethesda System for Reporting Thyroid Cytopathology (TBSRTC)}

The needle aspiration under ultrasound guidance is the most frequently used examination for diagnostic purposes [25]; however, the amount of material may be low or inadequate for diagnosis. In these cases, with high suspicion of malignancy, a core biopsy is recommended rather than FNAC repetition to increase the accuracy of percutaneous needle diagnostics, as a first-line tool in selected cases [26].

The Bethesda System for Reporting Thyroid Cytopathology (TBSRTC) regulates the management of patients after FNAC [27], as summarised in Table 1. 
Table 1. The Bethesda System for Reporting Thyroid Cytopathology (TBSRTC) classification.

\begin{tabular}{lcc}
\hline \multicolumn{1}{c}{ Diagnostic Category } & Risk of Malignancy (\%) & Recommendation \\
\hline $\begin{array}{l}\text { I. Non-diagnostic or unsatisfactory } \\
\text { II. Benign }\end{array}$ & $1-4$ & $\begin{array}{c}\text { Repeat FNAC with } \\
\text { Ultrasound guidance }\end{array}$ \\
\hline $\begin{array}{l}\text { III. AUS or FLUS } \\
\text { IV. Suspected follicular } \\
\text { neoplasm/Follicular neoplasm }\end{array}$ & $0-3$ & Clinical Follow-up \\
\hline $\begin{array}{l}\text { V. Suspected Malignancy } \\
\text { VI. Malignancy }\end{array}$ & $15-30$ & Repeat FNAC \\
\hline HUS Atyproidectomy
\end{tabular}

AUS: Atypia of undetermined significance; FLUS: follicular lesion of undetermined significance; FNAC: fineneedle aspiration cytology.

A difference exists for category IV (follicular neoplasm) cases which undergo hemithyroidectomy and category $\mathrm{V}$ (suspected malignancy) which undergo total thyroidectomy. Single cases of PDTC might be placed in either of these categories because of morphological overlapping, as previously mentioned, but surgical intervention is always recommended, given the malignant nature of PDTC. Furthermore, it has been reported that only $32.5 \%$ of PDTC cases are correctly diagnosed by FNAC, whose main feature appears to be the architectural pattern of cellular nests and three-dimensional clusters, along with loosely cohesive singly dispersed cells in the background. This latter feature represents a highly distinctive tract of PDTC.

In view of the controversy related to the interpretation of the cytological appearance, an integration with ultrasound findings might be useful in the intermediate (IV) Bethesda category, where completion of the thyroidectomy would be the safest approach if an initial lobectomy was performed. However, in cases where morphological features are indicative of TBSRTC category V or VI, a preoperative histological diagnosis before surgery is not necessary, as the treatment will not be affected.

\section{Immunohistochemistry}

In addition to the cytohistological tracts, the diagnosis is based on a panel of immunohistochemical stains, summarised in Table 2. Although PDTC loses the component of well-differentiated thyroid carcinoma, it produces thyroglobulin, contains colloids, and retains the ability to respond to radioactive iodine [28]. Furthermore, since it originates from a gland, it is derived from epithelial cells, thus maintaining the immunophenotypic characteristic of expressing cytokeratins, as reported by Dettmer et al. [29].

Table 2. Common immunohistochemical staining used in poorly differentiated thyroid carcinoma (PDTC).

\begin{tabular}{cc}
\hline Immunohistochemical Staining & PDTC \\
\hline Calcitonin & - \\
\hline Chromogranin A & no data \\
\hline Synaptophysin & no data \\
\hline Thyroglobulin & $-/+$ \\
\hline Galectin-3 & $-/+$ \\
\hline HBME-1 & + \\
\hline PanCK & $-/+$ \\
\hline TTF1 &
\end{tabular}


Table 2. Cont.

\begin{tabular}{cc}
\hline Immunohistochemical Staining & PDTC \\
\hline CK7 & $-/+$ \\
\hline CK19 & $-/+$ \\
\hline PAX8 & $-/+$ \\
\hline
\end{tabular}

\section{Molecular Biology}

BRAF and RAS mutations remain the principal genes involved in aggressive thyroid carcinomas, occurring in $33 \%$ and $45 \%$ of the PDTCs, respectively [30,31]. Notably, there is a correlation between the genes involved and the phenotype displayed, with $42 \%$ of RAS mutations in identifiable PDTCs according to both Turin proposal and MSKCC criteria, and with BRAF mutation only accounting for 78\% of the MSKCC-diagnosed PDTCs. Additionally, BRAF-mutated PDTCs are more frequently responsible for a loco-regional disease, while on the contrary, RAS-mutated follicular carcinomas tend to present with distant metastases.

It has also been demonstrated that the co-existence of BRAF/RAS and TERT genetic alterations has a detrimental impact on the aggressiveness of thyroid carcinoma. More specifically, TERT promoter and TP53 mutations, as well as PIK3CA-PTEN-AKT-mTOR pathway, SWI-SNG complex synergistically concur to worse outcomes in PDTC [32].

The median mutation burden detected in PDTC is 2 , and an above-median number of somatic mutations is associated with a larger tumour size of $>4 \mathrm{~cm}$, a higher frequency of distant metastasis, and shorter overall survival [30].

\section{TNM Classification}

In October 2016, the American Joint Committee on Cancer (AJCC) published the 8th edition of the AJCC/TNM cancer staging system, and it has been introduced in clinical practice since 1 January 2018 [33,34] (Table 3).

Table 3. TNM classification.

\begin{tabular}{c}
\hline \begin{tabular}{c} 
Primary tumour (pT): \\
TX: Primary tumour cannot be assessed \\
T0: No evidence of primary tumour \\
\hline T1: Tumour $\leq 2 \mathrm{~cm}$ in greatest dimension limited to the thyroid \\
\hline T1a: Tumour $\leq 1 \mathrm{~cm}$ in greatest dimension limited to the thyroid \\
\hline T1b: Tumour $>1 \mathrm{~cm}$ but $\leq 2 \mathrm{~cm}$ in greatest dimension limited to the thyroid \\
\hline T2: Tumour $>2 \mathrm{~cm}$ but $\leq 4 \mathrm{~cm}$ in greatest dimension limited to the thyroid \\
\hline T3: Tumour $>4$ cm limited to the thyroid or gross extrathyroidal extension invading only \\
strap muscles \\
\hline T3b: Gross extrathyroidal extension invading only strap muscles (sternohyoid, sternothyroid, \\
thyrohyoid, or omohyoid muscles) from a tumour of any size \\
\hline T4: Includes gross extrathyroidal extension into major neck structures \\
\hline T4a: Gross extrathyroidal extension invading subcutaneous soft tissues, larynx, trachea, \\
oesophagus, or recurrent laryngeal nerve from a tumour of any size \\
\hline T4b: Gross extrathyroidal extension invading prevertebral fascia or encasing carotid artery or \\
mediastinal vessels from a tumour of any size
\end{tabular} \\
\hline
\end{tabular}


Table 3. Cont.

\begin{tabular}{|c|}
\hline Regional lymph node $(\mathrm{pN})$ : \\
\hline NX: Regional lymph nodes cannot be assessed \\
\hline N0: No evidence of regional lymph node metastasis \\
\hline N0a: One or more cytologic or histologically confirmed benign lymph nodes \\
\hline N0b: No radiologic or clinical evidence of locoregional lymph node metastasis \\
\hline N1: Metastasis to regional nodes \\
\hline $\begin{array}{l}\text { N1a: Metastasis to level VI or VII (pretracheal, paratracheal, prelaryngeal/Delphian or upper } \\
\text { mediastinal) lymph nodes; this can be unilateral or bilateral disease }\end{array}$ \\
\hline $\begin{array}{l}\text { N1b: Metastasis to unilateral, bilateral, or contralateral lateral neck lymph nodes (levels I, II, III, } \\
\qquad \text { IV, or V) or retropharyngeal lymph nodes }\end{array}$ \\
\hline Distant metastasis $(\mathrm{M})$ : \\
\hline M0: No distant metastasis \\
\hline M1: Distant metastasis \\
\hline
\end{tabular}

\section{Management}

As for well-differentiated thyroid cancers, the initial phase is managed by the endocrinologist and the surgeon, with an adequate staging of the disease in a short time, the main requirement to correctly plan the treatment and achieve the best recurrence-free survival outcomes $[7,10]$. The initial diagnosis is clinical and cytohistological. The presence of rapidly growing thyroid nodule with a tendency to involve loco-regional structures (nodes), but also to eventually metastasise, is already clinically suggestive of an aggressive carcinoma. It is recommended to consider the clinical, US, and cytological major features including the rapid growth of a well-defined mass, as well as its heterogeneity and hypoechogenicity, trying to target the strong hypoechoic area when performing the FNAC. The same alert should rise for fast-growing suspicious lymph nodes, mainly at the subcortical area (where the metastatic cell nests develop; in fact, necrosis is often acellular and located centrally within the metastatic node), to give rise to the diagnosis of PDTC.

Yet, as previously mentioned, cytological diagnosis of PDTC based on FNAC is challenging, in view of the rarity of the disease, the nonspecific cytological features, the overlap with cytological characteristics of follicular neoplasms, and the frequent presence of the poorly differentiated component within the well-differentiated tumour.

Elimination of PDTC can be achieved by complete surgical removal and treatment of a limited loco-regional disease, with a high remission (94.3\%) [35], very close to that of well-differentiated carcinoma and superior to that of anaplastic carcinoma [36]. The increase in survival is associated with the young age ( $<60$ years), the limited size of the tumour, the absence of distant metastases, the co-existence of a well-differentiated thyroid tumour, and a greater extension of neck surgery, as indicated in Table 4, our single centre experience. Surgical intervention in operable cases involves total thyroidectomy associated with complete recurrent and lateral cervical lymphadenectomy. 
Table 4. Our single centre experience.

\begin{tabular}{|c|c|c|c|c|c|c|c|c|c|c|c|c|}
\hline $\mathbf{P t}$ & Sex & $\begin{array}{c}\text { Age } \\
\text { (Years) }\end{array}$ & $\begin{array}{c}\text { FU } \\
\text { (Months) }\end{array}$ & FNAC & $\underset{(\mathrm{mm})}{\mathrm{AP}}$ & $\begin{array}{c}\mathrm{T} \\
(\mathrm{mm})\end{array}$ & $\begin{array}{c}\mathrm{L} \\
(\mathrm{mm})\end{array}$ & Surgery & Histology & Lymphadenectomy & pT & $\mathrm{pN}$ \\
\hline 1 & M & 58 & 60 & - & - & - & - & TT & PDTC & $\begin{array}{c}\text { Radical } \\
\text { lymphadenectomy }+ \\
\text { laryngectomy }\end{array}$ & $4 a$ & $0 / 8$ \\
\hline 2 & $\mathrm{~F}$ & 85 & 24 & 4 & - & - & - & TT & PDTC & Periglandular nodes & $4 a$ & 1a $1 / 2$ \\
\hline 3 & M & 64 & 24 & 4 & 24 & 13 & 27 & TT & PDTC & $\begin{array}{l}2 \text { loco-regional } \\
\text { nodes }\end{array}$ & $4 a$ & $0 / 2$ \\
\hline 4 & $\mathrm{~F}$ & 54 & 24 & recurrence & $7.5 ; 18.9$ & $4.6 ; 8.8$ & $\begin{array}{c}11.6 \\
20\end{array}$ & $\begin{array}{l}\text { Nodule } \\
\text { removal }\end{array}$ & PDTC & - & - & - \\
\hline 4 & $\mathrm{~F}$ & 55 & 12 & recurrence $x 2$ & 0.08 & 0.05 & 0.05 & $\begin{array}{l}\text { Nodule } \\
\text { removal }\end{array}$ & PDTC & - & - & - \\
\hline 5 & $\mathrm{M}$ & 56 & 12 & 3 & 46 & 38 & 41 & TT & PDTC & $\mathrm{N}$ & $3 a$ & - \\
\hline 6 & $\mathrm{~F}$ & 55 & 12 & 3 & 50.8 & 37.7 & 61.2 & $\mathrm{TT}$ & Oncocytic & Latero-cervical II-IV & $3 b$ & $\begin{array}{c}1 \mathrm{~b} \\
(10 / 43)\end{array}$ \\
\hline 7 & $\mathrm{~F}$ & 80 & 12 & - & - & - & - & TT & PDTC & $\begin{array}{l}\text { Latero-cervical } \\
\text { III-IV-VI-VIII }\end{array}$ & 4 & $\begin{array}{c}1 b \\
6 / 44\end{array}$ \\
\hline
\end{tabular}

AP: anteroposterior diameter; FNAC: fine-needle aspiration cytology; FU: follow-up; L: lateral diameter; pN: primary nodes; pT: primary tumour; Pt: patient; T: transversal diameter; TT: total thyroidectomy.

Our previous experience also showed that the presence of lateral cervical lymph nodes at the time of diagnosis is higher for patients older than 71 years [37], confirming the significance of age as a prognostic factor, especially in thyroid cancers.

Finally, in terms of follow-up, given the differentiation of the thyroid cell, the use of thyroglobulin dosage in the follow-up is an indicator for relapse of the disease, and for the same reason, there is support for the use of a suppressive hormone replacement therapy or for the use of radioactive iodine (even in the presence of mixed forms). This is particularly relevant in the radioiodine-resistant forms, and even though chemotherapy is currently not standard of care, emerging positive effects have been reported into two large trials [38,39], in which monoclonal antibodies, sorafenib and lenvatinib, were administered.

\section{Conclusions}

Poorly differentiated thyroid carcinoma diagnosis is challenging; thus, this disease might remain underdiagnosed. The Turin proposal—namely, a high mitotic index and a solid/trabecular or insular pattern, are the most broadly in use diagnostic algorithm, and it is important to determine the percentage of poorly differentiated disease to correctly estimate recurrence-free survival and plan treatment accordingly. The genetic landscape of PDTC is in continuous evolution and surgical radical treatment offers excellent survival.

Author Contributions: Conceptualization: M.I.B., M.B., L.G., V.D., R.P.; methodology: M.I.B., L.G., V.D.; validation: M.B., V.D., L.G.; formal analysis: T.G., R.M. (Rosa Menditto), A.M., M.S., L.V.; investigation: M.B., L.G.; resources: M.I.B., M.B., R.P., L.G., M.C.B., M.L.C., R.M. (Rossella Melcarne), C.S., V.D.; data curation: M.I.B., M.B., L.G., V.D.; writing: M.I.B., writing-review and editing, L.G., V.D., R.P.; supervision: L.G., V.D. All authors have read and agreed to the published version of the manuscript.

Funding: No external source funded this study.

Institutional Review Board Statement: The study, performed in accordance to the Declaration of Helsinki principles, is a retrospective analysis. The data used were anonymised; the study did not require patient or public involvement nor affected patient care. The study fell under the category of research through the use of anonymised data of existing databases which, based on the Health Research Authority criteria, does not require proportional or full ethics review and approval.

Informed Consent Statement: As a retrospective chart analysis, no informed consent was required.

Data Availability Statement: The data used to support the findings of this study are included within the article and are available on request from the corresponding author.

Conflicts of Interest: The authors declare no conflict of interest. 


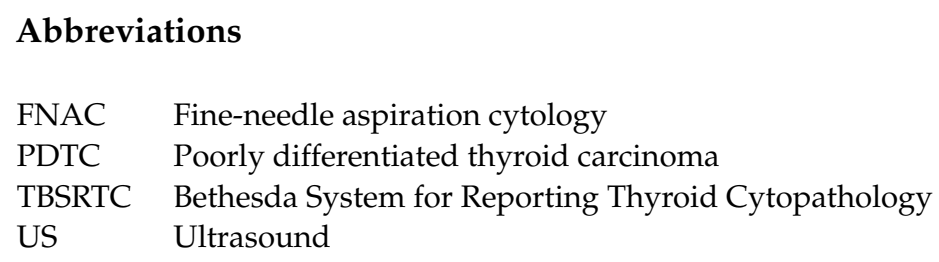

\section{References}

1. Kim, M.-H.; Lee, T.H.; Lee, J.S.; Lim, D.-J.; Lee, P.C.-W. Hif-1 $\alpha$ Inhibitors Could Successfully Inhibit the Progression of Differentiated Thyroid Cancer in Vitro. Pharmaceuticals 2020, 13, 208. [CrossRef]

2. Dettmer, M.; Schmitt, A.; Steinert, H.; Haldemann, A.; Meili, A.; Moch, H.; Komminoth, P.; Perren, A. Poorly differentiated thyroid carcinomas: How much poorly differentiated is needed? Am. J. Surg. Pathol. 2011, 35, 1866-1872. [CrossRef]

3. Kakudo, K.; Bai, Y.; Katayama, S.; Hirokawa, M.; Ito, Y.; Miyauchi, A.; Kuma, K. Classification of follicular cell tumors of the thyroid gland: Analysis involving Japanese patients from one institute. Pathol. Int. 2009, 59, 359-367. [CrossRef]

4. Sanders, E.M., Jr.; LiVolsi, V.A.; Brierley, J.; Shin, J.; Randolph, G.W. An evidence-based review of poorly differentiated thyroid cancer. World J. Surg. 2007, 31, 934-945.

5. Asioli, S.; Erickson, L.A.; Righi, A.; Jin, L.; Volante, M.; Jenkins, S.; Papotti, M.; Bussolati, G.; Lloyd, R.V. Poorly differentiated carcinoma of the thyroid: Validation of the Turin proposal and analysis of IMP3 expression. Mod. Pathol. 2010, 23, 1269-1278. [CrossRef] [PubMed]

6. Ibrahimpasic, T.; Ghossein, R.; Shah, J.P.; Ganly, I. Poorly Differentiated Carcinoma of the Thyroid Gland: Current Status and Future Prospects. Thyroid 2019, 29, 311-321. [CrossRef] [PubMed]

7. Lee, D.Y.; Won, J.-K.; Lee, S.-H.; Park, D.J.; Jung, K.C.; Sung, M.-W.; Wu, H.-G.; Kim, K.H.; Park, Y.J.; Hah, J.H. Changes of Clinicopathologic Characteristics and Survival Outcomes of Anaplastic and Poorly Differentiated Thyroid Carcinoma. Thyroid 2016, 26, 404-413. [CrossRef]

8. Grani, G.; Ramundo, V.; Falcone, R.; Lamartina, L.; Montesano, T.; Biffoni, M.; Giacomelli, L.; Sponziello, M.; Verrienti, A.; Schlumberger, M.; et al. Thyroid Cancer Patients with No Evidence of Disease: The Need for Repeat Neck Ultrasound. J. Clin. Endocrinol. Metab. 2019, 104, 4981-4989. [CrossRef] [PubMed]

9. Fresilli, D.; David, E.; Pacini, P.; Del Gaudio, G.; Dolcetti, V.; Lucarelli, G.; Di Leo, N.; Bellini, M.; D’Andrea, V.; Sorrenti, S.; et al. Thyroid Nodule Characterization: How to Assess the Malignancy Risk. Update of the Literature. Diagnostics 2021, 11, 1374. [CrossRef]

10. Lee, D.Y.; Won, J.-K.; Choi, H.S.; Park, D.J.; Jung, K.C.; Sung, M.-W.; Kim, K.H.; Hah, J.H.; Park, Y.J. Recurrence and Survival after Gross Total Removal of Resectable Undifferentiated or Poorly Differentiated Thyroid Carcinoma. Thyroid 2016, 26, 1259-1268. [CrossRef]

11. Hahn, S.Y.; Shin, J.H. Description and Comparison of the Sonographic Characteristics of Poorly Differentiated Thyroid Carcinoma and Anaplastic Thyroid Carcinoma. J. Ultrasound Med. 2016, 35, 1873-1879. [CrossRef] [PubMed]

12. Lacout, A.; Marcy, P.-Y. Highlights on power Doppler US of thyroid malignancy. Radiology 2010, 257, 586-587. [CrossRef]

13. Marcy, P.-Y.R.; Thariat, J.; Bozec, A.; Poissonnet, G.; Benisvy, D.; Dassonville, O. Venous obstruction of thyroid malignancy origin: The Antoine Lacassagne Institute experience. World J. Surg. Oncol. 2009, 7, 40. [CrossRef]

14. Lacout, A.; Marcy, P.Y.; Thariat, J. RE: Role of Duplex Doppler US for Thyroid Nodules: Looking for the "Sword" Sign. Korean J. Radiol. 2011, 12, 400-401. [CrossRef]

15. Dailey, M.E.; Lindsay, S.; Skahen, R. Relation of thyroid neoplasms to Hashimoto disease of the thyroid gland. Arch. Surg. 1955, 70, 291-297. [CrossRef] [PubMed]

16. Hyer, S.L.; Dandekar, P.; Newbold, K.; Haq, M.; Wechalakar, K.; Harmer, C. Thyroid cancer causing obstruction of the great veins in the neck. World J. Surg. Oncol. 2008, 6, 36. [CrossRef]

17. Ferreira, L.B.; Gimba, E.; Vinagre, J.; Sobrinho-Simões, M.; Soares, P. Molecular Aspects of Thyroid Calcification. Int. J. Mol. Sci. 2020, 21, 7718. [CrossRef]

18. Sakamoto, A.; Kasai, N.; Sugano, H. Poorly differentiated carcinoma of the thyroid. A clinicopathologic entity for a high-risk group of papillary and follicular carcinomas. Cancer 1983, 52, 1849-1855. [CrossRef]

19. Carcangiu, M.L.; Zampi, G.; Rosai, J. Poorly differentiated ("insular") thyroid carcinoma. A reinterpretation of Langhans' "wuchernde Struma". Am. J. Surg. Pathol. 1984, 8, 655-668. [CrossRef]

20. DeLellis, R.A.; Lloyd, R.V.; Heitz, P.U.; Eng, C. (Eds.) Pathology and Genetics of Tumours of Endocrine Organs; IARC Press: Lyon, France, 2004.

21. Volante, M.; Collini, P.; Nikiforov, Y.E.; Sakamoto, A.; Kakudo, K.; Katoh, R.; Lloyd, R.V.; LiVolsi, V.A.; Papotti, M.; SobrinhoSimoes, M.; et al. Poorly Differentiated Thyroid Carcinoma: The Turin Proposal for the Use of Uniform Diagnostic Criteria and an Algorithmic Diagnostic Approach. Am. J. Surg. Pathol. 2007, 31, 1256-1264. [CrossRef] [PubMed]

22. Volante, M.; Bussolati, G.; Papotti, M. The story of poorly differentiated thyroid carcinoma: From Langhans' description to the Turin proposal via Juan Rosai. Semin. Diagn. Pathol. 2016, 33, 277-283. [CrossRef] 
23. Hiltzik, D.; Carlson, D.L.; Tuttle, R.M.; Chuai, S.; Ishill, N.; Shaha, A.; Shah, J.P.; Singh, B.; Ghossein, R.A. Poorly differentiated thyroid carcinomas defined on the basis of mitosis and necrosis: A clinicopathologic study of 58 patients. Cancer 2006, 106, 1286-1295. [CrossRef] [PubMed]

24. Önenerk, M.; Canberk, S.; Güneş, P.; Erkan, M.; Kilicoglu, G.Z. Oncocytic variant of poorly differentiated thyroid carcinoma: “Is diagnosis possible by fine-needle aspiration?". CytoJournal 2016, 13, 23. [CrossRef] [PubMed]

25. Bellevicine, C.; Vigliar, E.; Malapelle, U.; Pisapia, P.; Conzo, G.; Biondi, B.; Vetrani, A.; Troncone, G. Cytopathologists can reliably perform ultrasound-guided thyroid fine needle aspiration: A 1-year audit on 3715 consecutive cases. Cytopathology 2015, 27, 115-121. [CrossRef]

26. Jung, C.K.; Baek, J.H. Recent Advances in Core Needle Biopsy for Thyroid Nodules. Endocrinol. Metab. 2017, 32, 407-412. [CrossRef]

27. Melo-Uribe, M.A.; Sanabria, Á.; Romero-Rojas, A.; Pérez, G.; Vargas, E.J.; Gutiérrez, V.; Abaúnza, M. The Bethesda system for reporting thyroid cytopathology in Colombia: Correlation with histopathological diagnoses in oncology and non-oncology institutions. J. Cytol. 2015, 32, 12-16. [CrossRef] [PubMed]

28. Dettmer, M.S.; Schmitt, A.; Komminoth, P.; Perren, A. Poorly differentiated thyroid carcinoma: An underdiagnosed entity. Pathologe 2020, 40, 227-234. [CrossRef]

29. Durante, C.; Tallini, G.; Puxeddu, E.; Sponziello, M.; Moretti, S.; Ligorio, C.; Cavaliere, A.; Rhoden, K.J.; Verrienti, A.; Maranghi, M.; et al. BRAF(V600E) mutation and expression of proangiogenic molecular markers in papillary thyroid carcinomas. Eur. J. Endocrinol. 2011, 165, 455-463. [CrossRef]

30. Landa, I.; Ibrahimpasic, T.; Boucai, L.; Sinha, R.; Knauf, J.A.; Shah, R.; Dogan, S.; Ricarte-Filho, J.C.; Krishnamoorthy, G.P.; Xu, B.; et al. Genomic and transcriptomic hallmarks of poorly differentiated and anaplastic thyroid cancers. J. Clin. Investig. 2016, 126, 1052-1066. [CrossRef]

31. Sykorova, V.; Dvorakova, S.; Vcelak, J.; Vaclavikova, E.; Halkova, T.; Kodetova, D.; Lastuvka, P.; Betka, J.; Vlcek, P.; Reboun, M.; et al. Search for new genetic biomarkers in poorly differentiated and anaplastic thyroid carcinomas using next generation sequencing. Anticancer Res. 2015, 35, 2029-2036.

32. Xu, B.; Ghossein, R. Genomic Landscape of poorly Differentiated and Anaplastic Thyroid Carcinoma. Endocr. Pathol. 2016, 27, 205-212. [CrossRef]

33. Amin, M.B.; Greene, F.L.; Edge, S.B.; Compton, C.C.; Gershenwald, J.E.; Brookland, R.K.; Meyer, L.; Gress, D.M.; Byrd, D.R.; Winchester, D.P. The Eighth Edition AJCC Cancer Staging Manual: Continuing to build a bridge from a population-based to a more "personalized" approach to cancer staging. CA Cancer J. Clin. 2017, 67, 93-99. [CrossRef]

34. Tuttle, R.M.; Haugen, B.; Perrier, N.D. Updated American Joint Committee on Cancer/Tumor-Node-Metastasis Staging System for Differentiated and Anaplastic Thyroid Cancer (Eighth Edition): What Changed and Why? Thyroid 2017, 27, 751-756. [CrossRef] [PubMed]

35. Ibrahimpasic, T.; Ghossein, R.; Carlson, D.L.; Chernichenko, N.; Nixon, I.; Palmer, F.L.; Lee, N.Y.; Shaha, A.R.; Patel, S.G.; Tuttle, R.M.; et al. Poorly Differentiated Thyroid Carcinoma Presenting with Gross Extrathyroidal Extension: 1986-2009 Memorial Sloan-Kettering Cancer Center Experience. Thyroid 2013, 23, 997-1002. [CrossRef] [PubMed]

36. Conzo, G.; Polistena, A.; Calò, P.G.; Bononi, P.; Gambardella, C.; Mauriello, C.; Tartaglia, E.; Avenia, S.; Sanguinetti, A.; Medas, F.; et al. Efficacy of combined treatment for anaplastic thyroid carcinoma: Results of a multinstitutional retrospective analysis. Int. J. Surg. 2014, 12, S178-S182. [CrossRef]

37. Falvo, L.; Catania, A.; Sorrenti, S.; D'Andrea, V.; Berni, A.; De Stefano, M.; De Antoni, E. Prognostic significance of the age factor in the thyroid cancer: Statistical analysis. J. Surg. Oncol. 2004, 88, 217-222. [CrossRef] [PubMed]

38. Brose, M.S.; Nutting, C.M.; Jarzab, B.; Elisei, R.; Siena, S.; Bastholt, L.; de la Fouchardiere, C.; Pacini, F.; Paschke, R.; Shong, Y.K.; et al. Sorafenib in radioactive iodine-refractory, locally advanced or metastatic differentiated thyroid cancer: A randomised, double-blind, phase 3 trial. Lancet 2014, 384, 319-328. [CrossRef]

39. Schlumberger, M.; Tahara, M.; Wirth, L.J.; Robinson, B.; Brose, M.S.; Elisei, R.; Habra, M.A.; Newbold, K.; Shah, M.H.; Hoff, A.O.; et al. Lenvatinib versus Placebo in Radioiodine-Refractory Thyroid Cancer. N. Engl. J. Med. 2015, 372, 621-630. [CrossRef] 